\title{
THE PERFORMANCE OF PATIENTS WITH ANKYLOSING SPONDYLITIS IN THE MAXIMUM VENTILATORY CAPACITY TEST
}

\author{
BY \\ JOHN L. D'SILVA, D. E. FREELAND, AND G. KAZANTZIS \\ From the Departments of Physiology and of Physical Medicine, London Hospital, London, E.I
}

(RECEIVED FOR PUBLICATION FEBRUARY 14, 1952)

Since described by Hermannsen in 1933, the maximum breathing capacity test has been widely used to obtain information about the overall mechanical function of the lungs. Recently Bernstein and Mendel (1951) studied the sources of error attributable to the apparatus in the test as commonly performed, and as a result of this work designed a spirometer which was substantially free from recording error (Bernstein, D'Silva, and Mendel, 1952).

No systematic investigation has been attempted in the past of the various factors which contribute to the amount of air respired by a subject submitted to the test. With a spirometer which records accurately the tidal air volumes of rapid breathing, systematic investigation becomes possible, and Bernstein and others (1952) demonstrated that the maximum voluntary ventilatory capacity (M.V.C.) depended on the number of respirations per minute (R.P.M.) used in the test.

In this paper, the importance of the movements of the ribs has been studied by comparing the performance of a group of normal young men with a group of young men with ankylosing spondylitis.

The maximum ventilatory capacity (M.V.C.) has been defined previously (D'Silva and Mendel, 1950) and is given by the formula:

M.V.C. in litres $/ \mathrm{min}$. $=$ Tidal air volume at $x$ R.P.M. $\times x$.

Particular attention has been paid in this investigation to the percentage of the vital capacity volume used in maximal breathing at a known respiratory rate. The term "swept fraction" has been used to denote this percentage (by analogy with the movements of a piston in a cylinder) and is given by the formula:

Swept fraction at $x$ R.P.M. $=$ $\frac{\text { Tidal air volume at } x \text { R.P.M. }}{\text { Vital capacity volume }} \times 100$.
The Subjects Forming the Basis of Study

The patients with ankylosing spondylitis were attending the Department of Physical Medicine. One of us (D.E.F.) selected all adult males under the age of 35 years and 14 consecutive patients were tested.

There was no doubt about the diagnosis in any of these cases. They suffered different degrees of disability from the rigid, fixed bamboo spine to relatively slight restriction of movements of the spine and ribs. Every patient had received physiotherapy and a course of $x$-ray therapy. None of the patients experienced pain on deep breathing at the time of the test or had symptoms referable to the lungs or cardiovascular system.

The control group of subjects numbered 16 men, all under the age of 35 . They were attending the Department of Physical Medicine or the Orthopaedic Department as out-patients. None experienced pain on breathing deeply, nor were any suffering from respiratory or cardiovascular disease.

\section{Physical Characteristics of the Subjects}

Table I provides a comparison of the physical characteristics of the control and experimental groups and records the statistical probability that

TABLE I

PHYSICAL CHARACTERISTICS OF PATIENTS WITH ANKYLOSING SPONDYLITIS AND OF CONTROLS

\begin{tabular}{|c|c|c|c|}
\hline & $\begin{array}{c}16 \\
\text { Controls }\end{array}$ & $\mathbf{P}$ & $\stackrel{14}{\text { Patients }}$ \\
\hline 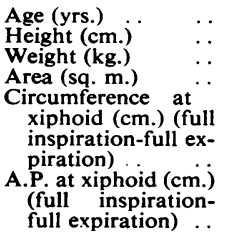 & $\begin{aligned} 24.3 & \pm 3.9 \\
172.8 & \pm 6 \cdot 8 \\
68 \cdot 3 & \pm 8 \cdot 9 \\
1.79 & \pm 0.13\end{aligned}$ & $\begin{array}{l}0.9>P>0.8 \\
0.05>P>0.02 \\
0.2>P>0.1\end{array}$ & $\begin{aligned} 28 \cdot 7 & =5.3 \\
171 \cdot 2 & \pm 6.4 \\
60.7 & \pm 8 \cdot 7 \\
1.70 & =0.14\end{aligned}$ \\
\hline
\end{tabular}


the differences could have been obtained by chance. It will be seen that the patients are slightly lighter than the controls, but the most marked difference between the two groups is the considerably reduced circumferential chest expansion (at the xiphisternum) of the patients with ankylosing spondylitis. Their antero-posterior expansion (measured at the level of the xiphisternum) was not significantly different from that of the controls.

\section{Conduct of THE Tests}

The tests included determinations of vital capacity volumes and of maximum ventilatory capacity at known rates of breathing.

For vital capacity determinations, the subject was asked to breathe out as deeply as he was able into the spirometer following a maximal inspiration. The volume was taken as the mean of three to six such expirations.

The subject was then asked to hold the mask tightly against his face, and to breathe in and out of the spirometer through his mouth as deeply as possible in time to a metronome. For the test at 30 R.P.M. the metronome was set at a rate of 60 , so that the subject breathed either in or out to each beat. The operator assisted by conducting in time and continually encouraging the subject to keep up his maximal ventilation. Most subjects performed satisfactorily on the first occasion, and all were able to keep to time. Maximal ventilation was performed for a period of not less than 15 secs.

The performance was considered satisfactory if the tidal excursions on the respiratory tracing were on the same horizontal level and of approximately the same size. Sloping tracings indicated an air leak between subject and facepiece and were discarded. Grossly unequal tidal excursions showed that each breath was not a maximal effort. Subjects who produced such a tracing had the test reexplained to them and were able to perform satisfactorily at the second attempt. Of the 16 subjects in whom the repeatability of the test was investigated, only two were unable to perform satisfactorily at the first attempt.

The mean tidal air of at least eight consecutive respirations, and the M.V.C. in litres per minute were calculated for the respiratory rate used. The mean tidal air at each respiratory rate was expressed as a percentage of the vital capacity volume of each subject, i.e., the swept fraction.

\section{Repeatability of Maximum Ventilatory Capacity (M.V.C.) Test}

Each of the 16 control subjects was asked to carry out two periods (about $15 \mathrm{sec}$. each) of

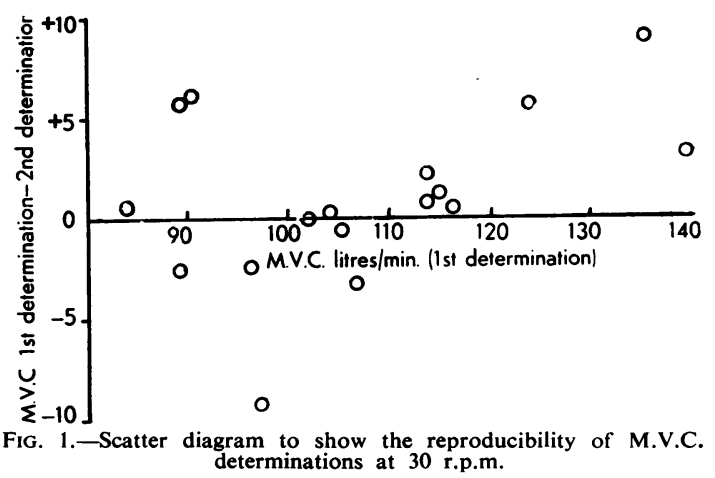

maximum voluntary ventilation at a respiratory rate of 30 a minute. There was a suitable interval between the two periods of maximum breathing. The M.V.C. in litres per minute was calculated for each tracing.

The results are shown on a scatter diagram (Fig. 1) which relates the first determination of M.V.C. in each case to the difference, in litres per minute, between the two successive determinations. In these experiments, the second determination differed by less than 10 litres per minute from the first. The mean value of all the differences was +1.0 litre, S.D. \pm 4.2 litres, thus showing that the test was highly reproducible.

\section{Swept fraction of Patients with Ankylosing} SpONDYLITIS AND OF Normal SUbJects

Both groups were subjected to the tests described above.

The results of the tests are presented in a scatter diagram (Fig. 2) which relates the vital capacity volume of the individual with the swept fraction at 30 R.P.M. The vital capacity volumes of the subjects tested ranged from 1.91 to 6.42 litres, but in spite of this wide variation the fraction of the vital capacity volume used in maximum breathing was around $80 \%$ for all subjects. The vital capacity vo'umes of the patients with ankylosing spondylitis ranged from 1.91 to 4.35 litres (mean 3.37 ; S.D. \pm 0.77 ) and, of the normal subjects, from 4.22 to 6.42 litres (mean 4.97 ; S.D. \pm 0.62 ). The difference between these two means is highly significant $(\mathrm{P}<0.01)$. The mean swept fractions of the two groups were $83.5 \%($ S.D. $= \pm 6.1 \%)$ and $79.9 \%$ (S.D. $= \pm 6.8 \%)$ respectively. The difference between these means was not significant $(0.2>\mathrm{P}>0.1)$. It is clear, therefore, that in spite of the restriction of movement of the thoracic cage which resulted in a considerably reduced vital capacity volume, the patients with ankylosing spondylitis could use the vital capacity volumes which were available to them just as efficiently as the normal subjects. 
EFFect OF RESTRICTED MOVEMENTS OF THE Thoracic Cage in Normal Subjects

It seemed possible that the patients with ankylosing spondylitis might have been able to compensate, in some way, for the restriction of rib movement caused gradually by the disease process. The performance of each normal subject was therefore measured after the movements of the thoracic cage had been restricted. A considerable degree of restriction was imposed by a canvas waistcoat which was tightened by stout lacing. It was found that the subjects' reactions to the waistcoat varied. Some tolerated a considerable degree of restriction of rib movements and others felt discomfort when less restricted. If, after the waistcoat was tightened, a subject complained of discomfort, the lacing was loosened a little so that no one was asked to perform maximum breathing whilst uncomfortable.

Each normal subject was subjected to the following series of tests: (a) Three determinations of vital

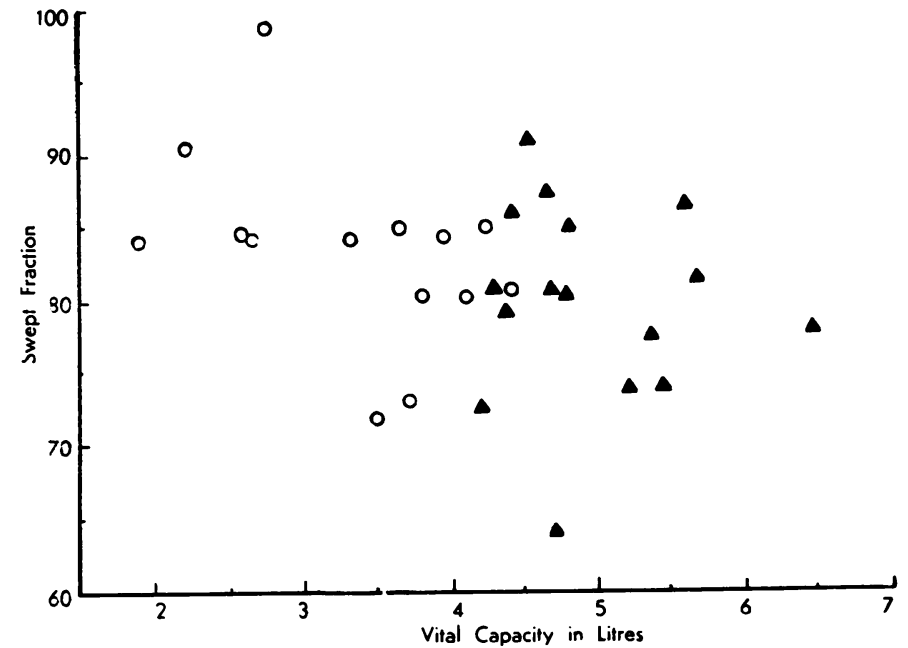

FIG. 2.-The relationship between the vital capacity volume and the swept fraction of normal subjects (triangles) and of patients with ankylosing spondylitis (circles). capacity volume; (b) maximum breathing at 30 R.P.M.; $(c)$ three determinations of vital capacity volume with the jacket on ; $(d)$ maximum breathing at 30 R.P.M. with the jacket on ; $(e)$ two determinations of vital capacity volume with the jacket on ; ( $f$ ) two determinations of vital capacity volume

TABLE II

TIDAL AIR AT 30 R.P.M. AS PERCENTAGE OF VITAL CAPACITY OF 16 CONTROL SUBJECTS WITH VITAL CAPACITY RESTRICTED AND UNRESTRICTED

\begin{tabular}{|c|c|c|c|c|c|c|}
\hline \multirow{3}{*}{ No. } & \multicolumn{2}{|c|}{ Unrestricted } & \multicolumn{2}{|c|}{ Restricted } & \multicolumn{2}{|c|}{ Unrestricted } \\
\hline & V.C. & $\begin{array}{c}\text { T.A. } \times 100 \\
30\end{array}$ & V.C. & $\left|\begin{array}{c}\text { T.A. } \times 100 \\
30\end{array}\right|$ & V.C. & $\underset{30}{\text { T.A. } \times 100}$ \\
\hline & 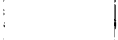 & V.C. & & V.C. & & V.C. \\
\hline $\begin{array}{r}1 \\
2 \\
3 \\
4 \\
5 \\
6 \\
7 \\
8 \\
9 \\
10 \\
11 \\
12 \\
13 \\
14 \\
15 \\
16\end{array}$ & \begin{tabular}{|c|}
$6 \cdot 42$ \\
$5 \cdot 69$ \\
$5 \cdot 62$ \\
$5 \cdot 53$ \\
5.40 \\
$5 \cdot 24$ \\
$4 \cdot 82$ \\
$4 \cdot 81$ \\
$4 \cdot 76$ \\
$4 \cdot 71$ \\
$4 \cdot 70$ \\
$4 \cdot 64$ \\
$4 \cdot 39$ \\
$4 \cdot 29$ \\
$4 \cdot 24$ \\
$4 \cdot 22$ \\
\end{tabular} & $\begin{array}{l}77.9 \\
82.0 \\
86.5 \\
74.8 \\
77.4 \\
74 \cdot 2 \\
84.7 \\
80 \cdot 8 \\
63.5 \\
87.6 \\
80 \cdot 8 \\
91 \cdot 5 \\
85 \cdot 7 \\
78 \cdot 2 \\
81 \cdot 0 \\
72.9\end{array}$ & $\begin{array}{l}4 \cdot 79 \\
4 \cdot 18 \\
4.27 \\
3.92 \\
4.05 \\
2.04 \\
3.40 \\
3.42 \\
3.04 \\
2.92 \\
3.81 \\
3.44 \\
3.09 \\
3.75 \\
3 \cdot 51 \\
2.54\end{array}$ & $\begin{array}{l}74 \cdot 7 \\
84 \cdot 5 \\
81 \cdot 4 \\
79 \cdot 5 \\
69 \cdot 3 \\
84 \cdot 3 \\
87.7 \\
79 \cdot 7 \\
69 \cdot 2 \\
87 \cdot 5 \\
71 \cdot 7 \\
81 \cdot 2 \\
99 \cdot 6 \\
76.0 \\
83.1 \\
83.1\end{array}$ & $\begin{array}{l}6 \cdot 59 \\
5 \cdot 56 \\
5 \cdot 45 \\
5 \cdot 72 \\
5 \cdot 50 \\
5 \cdot 18 \\
4 \cdot 94 \\
4 \cdot 57 \\
4.67 \\
4 \cdot 74 \\
\\
5 \cdot 01 \\
4 \cdot 68 \\
4 \cdot 31 \\
4 \cdot 18 \\
4 \cdot 02\end{array}$ & $\begin{array}{l}77 \cdot 6 \\
89 \cdot 5 \\
\\
77 \cdot 0 \\
68 \cdot 4 \\
84.4 \\
84.1 \\
65 \cdot 7 \\
87 \cdot 9 \\
84.0 \\
80 \cdot 7 \\
75 \cdot 8 \\
82.5\end{array}$ \\
\hline $\begin{array}{l}\text { Mean } \\
\text { S.D. }\end{array}$ & $\begin{array}{l}4.97(a) \\
=0.62\end{array}$ & $\begin{array}{r}79.9(\mathrm{~d}) \\
\pm 6.84\end{array}$ & $\begin{array}{r}3.51(b) \\
\pm 0.69\end{array}$ & $\begin{array}{r}80 \cdot 8(\mathrm{e}) \\
+7.73\end{array}$ & $\begin{array}{r}5.0 \text { (c) } \\
+0.68\end{array}$ & $\begin{array}{c}79 \cdot 8 \\
+\quad 7 \cdot 28\end{array}$ \\
\hline
\end{tabular}

$\mathbf{P}$ for $(a)$ and $(b)=\mathbf{P}<0.01 ; P$ for $(a)$ and $(c)=0.9>\mathbf{P}>0.8$; $\mathbf{P}$ for $(d)$ and $(e)=0.8>\mathbf{P}>0.7$. after removing the jacket; $(g)$ in most of the subjects, maximum breathing at 30 R.P.M. after removing the jacket.

The results are shown in Table II and in Figs. 3 and 4.

Table II, column 2, shows the vital capacity (mean of three measurements) before restriction. Column 3 shows the unrestricted swept fraction; column 4 is the mean vital capacity volume measured before and after maximum breathing at 30 R.P.M. with the waistcoat adjusted $((c)$ and $(e)$

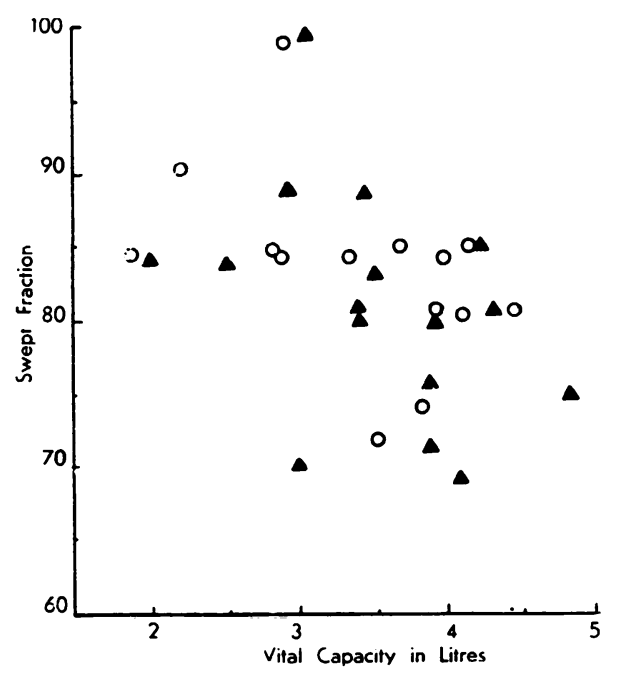

FIG. 3.-The relationship between the vital capacity volume and the swept fraction of normal subjects with rib movements restricted by a canvas waistcoat (triangles) and of patients with ankylosing spondylitis (circles). 


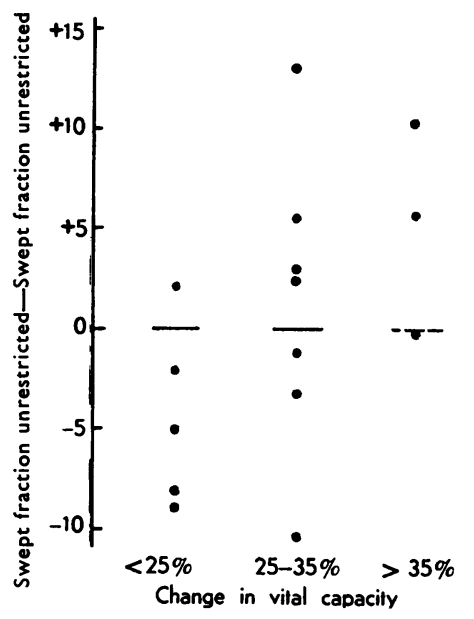

FIG. 4.-The effect on the swept fraction of restricting the rib movements of normal subjects.

above, mean of five determinations); column 5 shows the swept fraction when restricted ; column 6 shows the vital capacity after removal of the restricting jacket $(f)$ above, mean of two determinations); column 7 shows the swept fraction when the restricting jacket had been removed.

Table II (columns 2 and 4) also shows the extent to which the vital capacity volumes of the different subjects were restricted by the waistcoat and also (columns 2 and 6) that, after removing the waistcoat, the vital capacity volumes returned, on the average, to their original values. In only three subjects (Nos. 8, 12, and 13) was there a difference of more than $200 \mathrm{ml}$. between the vital capacity volumes before and after restriction and in one of these (No. 12) it was greater than $300 \mathrm{ml}$.

With the thoracic cage restricted, the mean vital capacity volume after maximum breathing at 30 R.P.M. was 0.26 litres (S.D. $= \pm 0.19$ litres) greater than before the period of maximum breathing. This difference is unlikely to be due to chance $(\mathrm{P}<0.01)$, but it is not large. It is probably due to the fastenings of the waistcoat "giving" slightly.

The mean values of the swept fraction at 30 R.P.M. before, during, and after restricting the rib movements were the same (columns 3,5 , and 7 ), in spite of the large mean decrease in vital capacity volume produced by the jacket (columns 2 and 4 ).

In only four instances (Nos. 2, 6, 12, and 16) out of 12 in which determinations were made, did the swept fractions before and after restriction differ by more than $5 \%$. In only No. 16 was the difference greater than $7.5 \%$.

The performance of these normal subjects whose rib movements had been restricted by the jacket was in every way comparable with the perfor- mance of the patients with ankylosing spondylitis whose rib movements had been gradually restricted by the disease process, as is shown in Fig. 3.

\section{EfFect of Degree of Restriction of Vital Capacity Volume on Performance}

The degree of reduction in the normal subjects' vital capacity volume varied from $12.6 \%$ to $61.1 \%$ in the different experiments. The results are plotted on a scatter diagram in Fig. 4 in which three degrees of restriction of vital capacity volume (viz. $<25 \%, 25-35 \%$, and $>35 \%$ ) have been arbitrarily chosen. In each group, the swept fraction during restriction minus that before restriction has been plotted. With the lesser degrees of restriction, the wearing of the jacket appeared to lower the subject's swept fraction, whereas when the restriction was considerable the subject's swept fraction appeared to increase. The mean values in Table II (columns 3 and 5) suggest that this difference is insignificant.

EFFEct of Rate of Breathing on M.V.C. OF Patients with ANkylosing Spondylitis

The maximum voluntary ventilatory capacity of the group of 14 patients with ankylosing spondylitis was studied at 30,50 , and 70 respirations per minute. Fig. 5 shows the mean values at each rate of breathing, as well as the corresponding figures for a group of 14 normal students reported previously (Bernstein and others, 1952). It will be seen that at each rate of breathing the patients have a smaller M.V.C. (in litres/min.) than the normals. There is, however, a close similarity between the effect of rate of breathing on the maximum voluntary ventilatory capacity of the two groups. Bernstein and others (1952) have shown that the mean value of the M.V.C. of their group of 14 normal subjects at 50 R.P.M. was significantly greater than at 30 R.P.M. and significantly less than at 70 . The patients with ankylosing spondylitis behaved similarly. The mean value of their M.V.C. at 50 R.P.M. was significantly greater than at 30 R.P.M. $(P<0.01)$, and significantly less than at 70 $(P<0.01)$. The mean values at 30,50 , and 70 R.P.M. in the group of patients are related exponentially, as are the mean values for the normal subjects previously investigated (Bernstein and others, 1952).

\section{Discussion}

It has long been known that the vital capacity volumes of patients with ankylosing spondylitis are considerably below normal and so it is not surprising that the M.V.C. of patients with this disease are also low. The experiments described in this 


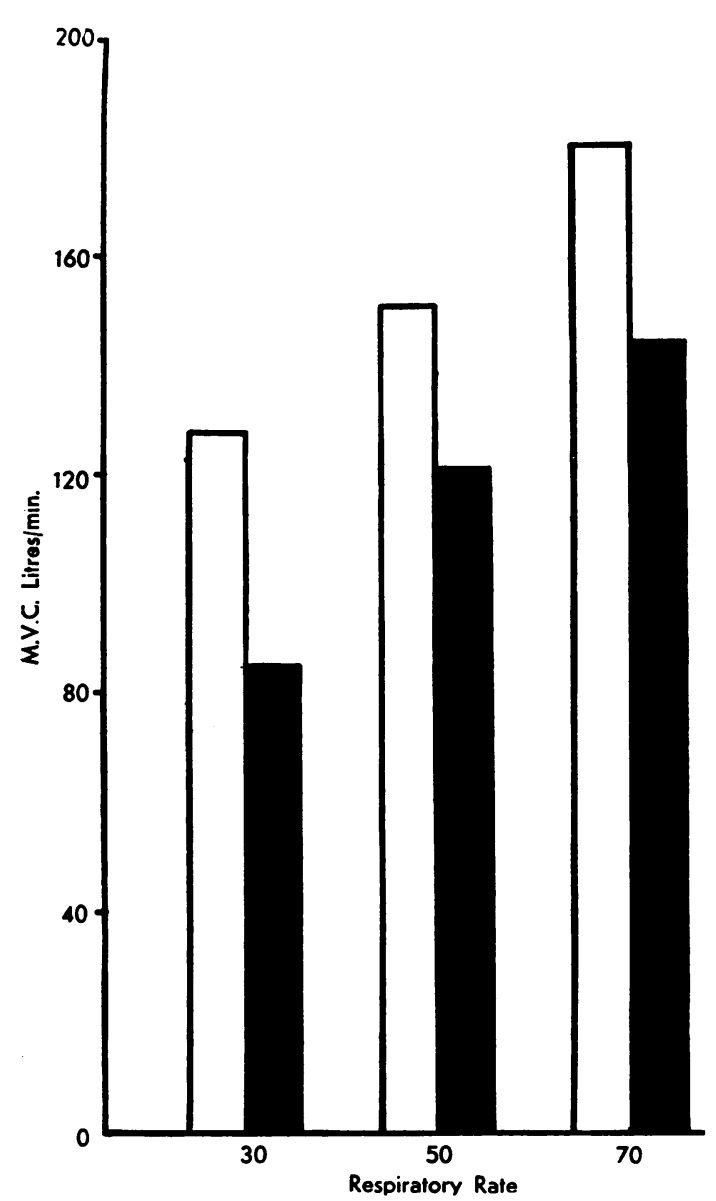

FIG. 5.-The effect of rate of breathing on the M.V.C. of normal subjects (white pillars) and of patients with ankylosing spondylitis (black pillars).

paper indicate that movements of the ribs contribute to the vital capacity volume, but in no way alter the fraction of this volume which can be used as tidal air in maximum voluntary deep breathing at 30 R.P.M.

Tiffeneau, Bousser, and Drutel (1949) investigated fast vital capacity tracings obtained from normal subjects. When a normal individual takes a maximum inspiration and a record is made of the rate at which he can expel his vital capacity volume in the shortest possible time, it is apparent that (a) the curve obtained is closely repeatable, and (b) the percentage of the vital capacity volume which subjects under 35 years of age can breathe out in one second is $86.2 \%$ (S.D. $= \pm 3.4 \%)$. Gaensler (1951) measured the fraction of the total vital capacity volume breathed out in the first second of the subject's fastest possible expiration after a maximal inspiration. For a group of normal subjects of various ages this fraction was $82.7 \%$. It has been shown that a normal subject performing maximum voluntary ventilation at 30 R.P.M. has a tidal air volume which, on the average, is $79.9 \%$ (S.D. $= \pm 6.8 \%$ ) of his vital capacity volume. In the M.V.C. test performed as described in this paper, expiration and inspiration are timed to be of equal duration, so that at 30 R.P.M. each lasts one second. It has been shown (Bernstein, D'Silva, and Mendel, 1952) that a normal subject performing maximum breathing at 30 R.P.M. uses that fraction of his vital capacity volume represented by his complemental air volume. It is not surprising therefore that the percentage of the vital capacity volume breathed out in one second during a determination of fast vital capacity is very near to the swept fraction during maximum breathing at 30 R.P.M. Because young patients with ankylosing spondylitis also have a swept fraction of $83.5 \%$ in the M.V.C. test, it is probable that the shape of their fast vital capacity curves is the same as those obtained from normal subjects. This hypothesis is supported by the experiments of Louyot, Girard, Sadoul, and Grilliat (1951), who measured the proportion of the vital capacity volume breathed out in the first second of a determination of fast vital capacity by patients with ankylosing spondylitis. Of the patients they studied, six were under 35 years of age and breathed out $85 \%$ (range 77 to $89 \%$ ) of the vital capacity volume in one second.

Restriction of rib movements, in an experiment of short duration, or by disease, is not completely compensated by increased diaphragmatic movement, as measurements of vital capacity show. The total muscular force available for respiration is contributed by the intercostal muscles, the diaphragm, and the accessory muscles of respiration. Gross restriction of the rib movements in normal subjects is without effect on the swept fraction, so that the performance of patients with ankylosing spondylitis cannot be attributed to any increased efficiency contributed by the diaphragm. The only common factor associated with the respiratory system in the three groups (normals, restricted normals, and patients with ankylosing spondylitis) is healthy lung tissue, so it is suggested that the swept fraction depends on the physical properties of the lung.

\section{SUMMARY}

The maximum ventilatory capacity (M.V.C.) at different respiratory rates was studied in three groups of subjects (1) normals, (2) normals wearing a restricting jacket, and (3) patients with ankylosing 
spondylitis. The M.V.C. in group (1) was much larger than in groups (2) and (3).

The percentage of the vital capacity volumes used in maximal breathing at each respiratory rate was estimated, and termed the swept fraction.

The swept fractions were similar in the three groups, and it is suggested that the swept fraction is dependent on the physical properties of the lung.
We are indebted to Dr. W. S. Tegner and Mr. H. Osmond-Clarke for allowing us to investigate their patients.

REFERENCES

Bernstein, L., D'Silya, J. L and Mendel, D. (1952). Thorax, 7, 255. (195i) Ibid., 6, 297.

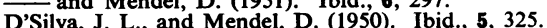

Gaensler, E., a. (1951). Amer. Rev. Tuberc., 64, 256.

Gaensler, E. A. (1951). Amer. Rev. Tuberc., 64, 256.

Hermannsen, J. (1933). Z. ges. exp. Med., 90, 130. (1951). Rev.

Louyot, P., Girard, J., Sadoul, P., and Grilliat, J. P. (1951). Rev.

Tiffeneau, R., Bousser, J., and Drutel, P. (1949). Paris méd., $39,543$. 